\title{
Childhood obesity management shifting from health care system to school system: intervention study of school-based weight management programme
}

\author{
Albert Lee ${ }^{1 *}$, Mandy $\mathrm{Ho}^{2}$, Vera MW Keung ${ }^{1}$ and Amy CM Kwong ${ }^{1}$
}

\begin{abstract}
Background: Home and school environments conducive for unhealthy eating and physical inactivity are precursors of obesity. The aim of this study is evaluation of the effectiveness of a multi-component school-based weight management programme for overweight and obese primary school children via a home-school joint venture.

Methods: This study made use of variety of behavioural modification strategies integrating into the Health Promoting School approach to promote healthy lifestyles. The participants were overweight and obese students aged between 8 and 12 from six participating schools. The interventions involved students attending ten 75 minutes after-school sessions and one 3-hour week-end session of practical interactive and fun activities on healthy eating and exercise, and meal plan together with parents and printed tailor-made management advices. Parents received an introductory seminar with 2 sets of specially designed exercise for their overweight children. The tools to measure bodyweight and fat percentage and standing height were bio-impedance body fat scale and a portable stadiometer. Self-administered questionnaire was used to measure knowledge, attitudes and behaviours. McNemar test was utilized to compare the proportions of behaviour changes within the same group to assess for the trends of changes. BMI z-score and body fat percentage of intervention participants at baseline, 4 month and 8 month were compared pair-wisely using tests of within subject contrasts in repeated measures ANOVA to assess for programme sustainability.
\end{abstract}

Results: Those students in the intervention group reduced their BMI $z$-score $(-0.21,95 \% \mathrm{Cl}-0.34$ to $-0.07, \mathrm{P}=0.003)$ and body fat $(-2.67 \%, 95 \% \mathrm{Cl}-5.12$ to $-0.22, \mathrm{P}=0.033)$ compared to wait list control group with statistical significant, and the intervention group also had a significant reduction in $\mathrm{BMI} z$-score $(-0.06,95 \% \mathrm{Cl}-0.11,-0.007, \mathrm{P}=0.028)$ and body fat $(-1.71 \%, 95 \% \mathrm{Cl},-3.44$ to $0.02, \mathrm{P}=0.052)$ after a 4 month maintenance period. Improvement of dietary habits and positive attitudes towards exercise were observed among the intervention group.

Conclusion: School based weight management programme integrated into a Health Promoting School approach with improved school policies and environment in supporting individual skills of obese students and their parents appears to be a promising practice for sustaining weight control.

Trial registration: ISRCTN58795797.

Keywords: Childhood obesity, School based programme, Intervention

\footnotetext{
*Correspondence: alee@cuhk.edu.hk

${ }^{1}$ Centre for Health Education and Health Promotion, JC School of Public Health and Primary Care, The Chinese University of Hong Kong, 4th Floor, Lek Yuen Health Centre, Shatin, New Territory, Hong Kong

Full list of author information is available at the end of the article
} 


\section{Background}

Prevalence of childhood obesity is rising globally and accelerates at faster rate among countries undergoing rapid economic development $[1,2]$. The prevalence of overweight and obesity among Chinese population especially mainland China, is fast catching up with the West [3]. There are already signs of epidemic of childhood obesity in Hong Kong, Taiwan and Macao [4,5]. Another emerging country, Brazil also shows similar pattern with increase from $4 \%$ to 14\% between 1974 and 1997 [6] with a shift towards the poor [7]. Childhood obesity poses immediate health concerns and long-term health risks [8], and social, emotional and psychological difficulties [9]. Obesity is now a significant risk factor accounting for the global burden of diseases [10]. It also poses problems in learning as shown by Iceland study that body mass index, diet and physical activity would explain up to $24 \%$ of the variance in academic performance after controlling major confounders [11].

A recent systematic review has reported that lifestyle interventions incorporating dietary and exercise components with or without behaviour therapy would lead to improvement of weight and cardio-metabolic outcomes among children [12]. Only two studies on Chinese population were included. One study was conducted in one middle school in Beijing China with 33 students receiving family based behavioural treatment and 35 students in control group [13], and the other study in Taiwan with 12 weeks heart health education and physical activity program [14].

Although general practitioners (GPs) as the first point of patient contact should be able to tackle the issue of childhood obesity, lack of experience, time and resources as well as guidelines on practical approach become the barriers [15]. Individualized interventions by GPs might not be intensive enough to bring about weight reduction for substantial behavioural modification [16,17]. Meta-analytic review of 64 obesity prevention programmes (46 trials) for children and adolescents did not reveal significant effects to prevent weight-gain [18]. Community based intervention with greater emphasis on environmental changes (both physical and social) has shown to be more effective as children's behaviours are much more environmental dependent $[19,20]$. Parental or family involvement in interventions would have impact on nutrition and physical activities of the children [21,22] leading to weight reduction [23].

School is another setting in which the children spend a substantial amount of time. Policies targeting the school environment can be considered as key strategy to address childhood obesity as school resources and practices would have impact on the availability of specific food and beverages [24]. Evidence has shown that home and school environments promoting unhealthy eating habit and physical inactivity are precursors of obesity [25]. Systematic reviews on school based obesity prevention programmes did not provide consistent evidence of the efficacy of school-based programme $[18,23,26,27]$. Most of the interventions focused on short-term changes right after the intervention [27-29], or process outcomes with no significant changes of behavioural outcomes [27,30,31]. Despite major reduction in consumption of high calorie beverages and snacks among intervention group in a randomised school-based intervention involving families and teachers to prevent excessive weight gain among adolescents in Brazil, no significant change of BMI was observed [32].

'Healthy Setting' approach such as Health Promoting School (HPS) delivers health promotion activities in the context of daily life and provides the 'social structures' to reach the defined population i.e., the students [33-36]. Schools adopting the HPS approach would be more willing to implement more intensive health promoting activities for the overweight and obese students so it is a potential avenue for more rigorous multi-component programme. This pilot study employed measures to evaluate the efficacy and sustainability of a 4 month schoolbased lifestyle intervention integrating into a boarder HPS approach on weight loss and behavioural changes in overweight and obese students by fostering individual focused weight management plan. This study also evaluated the impact of the interventions on their parents. To our knowledge, this is one of the very few studies delivered in schools which implemented a broader HPS initiative.

\section{Methods}

\section{Ethics statement}

The study has been registered with International Standard Randomised Controlled Trial Number Register (ISRCTN 58795797) and the study was vetted and approved by Subcommittee of Health Care Promotion Fund of Hong Kong SAR Government and recommended to Health Care Promotion Fund. The project also met the safety and ethical requirement of University. Inform parental consent was obtained and investigations were conducted according to the principles expressed in the declaration of Helsinki. The study was endorsed by the Chinese University of Hong Kong Faculty of Medicine Survey and Behavioural Research Ethics (SBER) Sub-committee, and approval was granted by University SBER to conduct survey on observation of human behaviours.

\section{Study design and setting}

The study was designed as a school-based intervention study adopting wait-list control approach over one academic year from August 2007 to July 2008. Invitation letters were sent to 65 primary schools participating in HPS project. Sixteen schools replied and based on the prevalence of obesity children in the school, school district, readiness of the school, and also similarity in sociodemographic background among participating schools, 6 schools were selected to participate. The schools were 
responsible to recruit eligible students for the program. The inclusion criteria were age 8 to 12 years, overweight or obese according to International Task Force definitions [37] with parents' commitment to participate in the homeschool joint venture. Informed written consent was obtained from parents prior to joining the project.

In Hong Kong, all students undergo anthropometric measurements annually with results recorded so teachers would identify overweight subjects. Teachers in Hong Kong are quite well equipped with skills in discussing sensitive issues such as overweight. They are quite comfortable to discuss the issues with students and parents if there is structured educational programme to help them emphasising positive living rather than negative images.

Within the school, those eligible subjects consented to participate were randomly assigned (random numbers) to start the program immediately (intervention group) or received the intervention 4 months later (wait-list control group). Due to difficulties in school administrative arrangement, only 4 primary schools were able to undertake both intervention and control groups while the other 2 schools only had students in the intervention group. The findings reported in this paper were based on data from the 4 schools with both intervention and control groups. Figure 1 illustrates the study design and participant's flow.

\section{Interventions}

This study piloted a tailor-made weight management plan for those overweight and obese children using combination of behavioural, dietary and physical activity interventions in school setting as well as home setting. The project team guided the participating schools to implement series of school-based activities promoting healthy eating and active lifestyles throughout the project period under the broad HPS approach enhancing the awareness of health lifestyle for all students (Additional file 1). This approach would reduce the contamination effect for the intervention group of students as they received the tailor-made weight management programme as well as whole school approach health promotion activities. It also reduced the co-interventions of students in wait-list control group as all students were involved in the general school based health promotion activities and they enrolled during second phase. This study evaluated the effectiveness of this multi-component weight management programme.

\section{Intervention program for overweight and obese students}

Intervention group received 4 months intensive intervention conducted by the dietician, nutritionist and physiotherapist of the project team as well as teachers of the participating schools followed by 4 months maintenance phase. The program consisted of ten 75-minutes afterschool sessions and 3 hours weekend session of practical, interactive and fun activities covering the topics on healthy eating, exercise and positive self-image. The sessions included 5 nutrition education sessions, 1 session on body image and self-esteem, 1 session on sport safety and 4 sessions of supervised physical activity (Table 1 ). Strategies such as assessing readiness for change, goalsetting, self-monitoring, problem-solving, role-playing, motivational reinforcement and awards were adopted to enhance behavioural modification. Teaching strategies included interactive games, practical workshops, problemsolving activities, fun-based physical activity. A meal plan (1500 to $1800 \mathrm{kcal} /$ day according to their age and sex, 50 to $55 \%$ total energy from carbohydrate, 15 to $20 \%$ from protein and $30 \%$ from fat) was provided for all participants in the presence of their parents at the start. Students also received printed tailor-made weight management advices. The dietetic advice included suggestions on portion of core food groups and snacks; food selection and healthy eating strategies. Exercise plans consisted of prescription on aerobic, stretching and strengthening exercise as well as suggestions on strategies to be more physical active.

\section{Involvement of parents}

Parents of intervention group received an introductory seminar on the basic principles, skills and knowledge on weight management at the beginning of the programme. Two sets of exercise specially designed for overweight children were introduced to parents together with their children so they would practise together at home. Parents received two sessions of 1-hour follow-up on further skills about healthy eating and exercise strategies to assist weight control in children. During the follow-up sessions, the dietician and physiotherapist discussed with parents in group to monitor students' progress at home and provided solutions for problems encountered. Parents were also invited to join the food label education training together with their children. Results of anthropometric measurement together with dietary and excise advice were explained to parents together with their children immediately after each assessment to enhance their awareness. Parents were encouraged to convert their enquiries to the project team via school teachers if they could not attend the planned workshop or face-to-face consultation. Student handbook contained a designated section that required parents to give weekly comments on their children's progress.

\section{Outcome measures}

Outcome measures were assessed at baseline $\left(\mathrm{T}_{0}\right)$ before the intervention, and completion of 4 months intervention $\left(T_{1}\right)$ to evaluate the effectiveness of program and 8 months from baseline, $\mathrm{T}_{2}$ (after the 4-months maintenance period) to evaluate the sustainability of the program. The primary study outcomes were age- and sexadjusted Body Mass Index z-score (BMI z-score) and body 


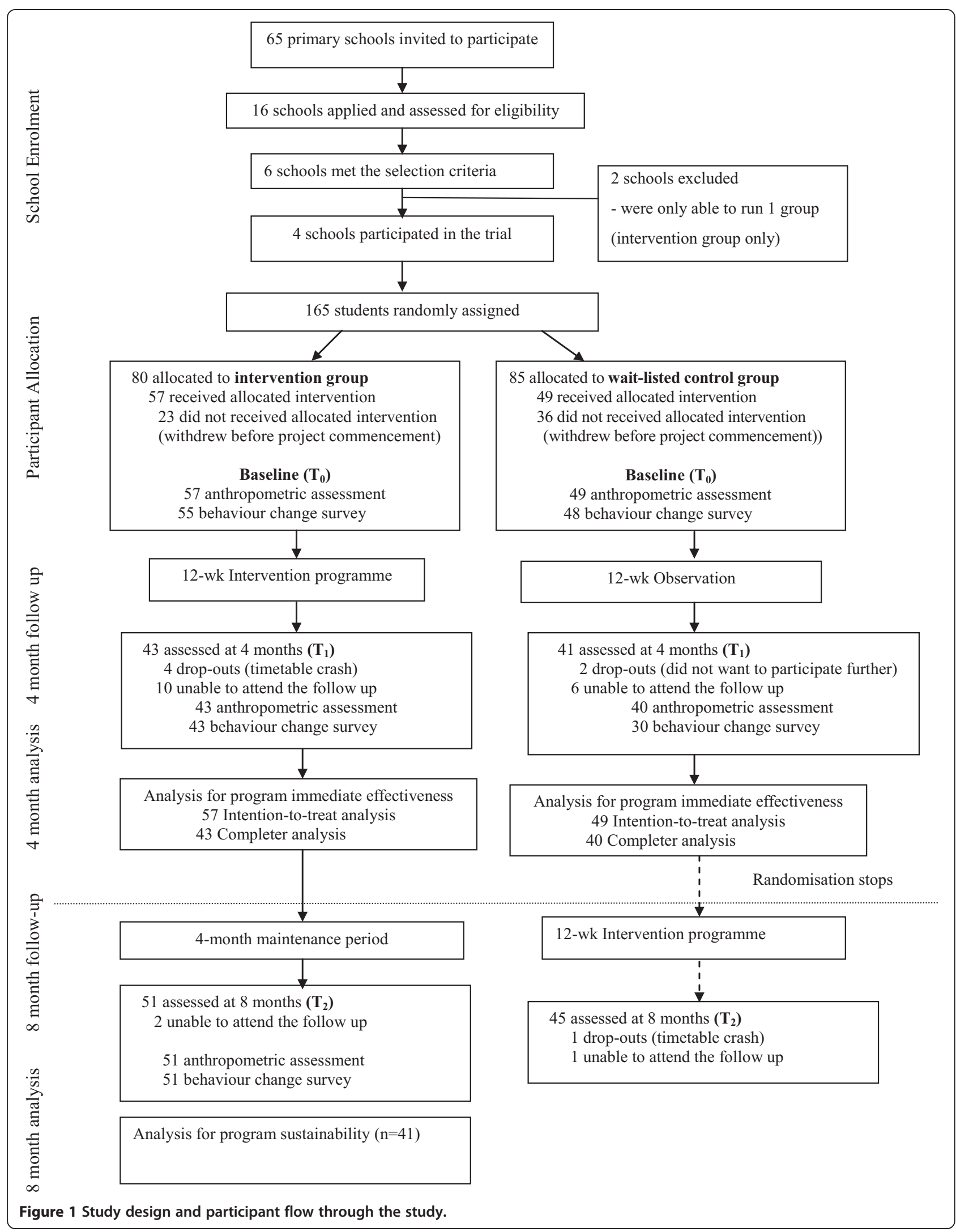




\begin{tabular}{|c|c|c|}
\hline Session & Topics & $\begin{array}{l}\text { Session } \\
\text { conducted by }\end{array}$ \\
\hline 1 & $\begin{array}{l}\text { Goal setting and introduction } \\
\text { of serve sizes }\end{array}$ & Nutritionist/dietician \\
\hline 2 & $\begin{array}{l}\text { Exercise and energy expenditure, } \\
\text { sport safety }\end{array}$ & Physiotherapy \\
\hline 3 & $\begin{array}{l}\text { Supervised physical activity } \\
\text { session I* }\end{array}$ & School PE teachers \\
\hline 4 & Body image and self esteem & School teacher \\
\hline 5 & $\begin{array}{l}\text { Energy balance and smart tips } \\
\text { for weight control }\end{array}$ & Nutritionist/dietician \\
\hline 6 & $\begin{array}{l}\text { Supervised physical } \\
\text { activitysession } \|^{*}\end{array}$ & School PE teachers \\
\hline 7 & Healthy snack & Nutritionist/dietician \\
\hline 8 & Label reading & Nutritionist/dietician \\
\hline 9 & $\begin{array}{l}\text { Supervised physical activity } \\
\text { session } \|^{*}\end{array}$ & School PE teachers \\
\hline 10 & Smart dinning out & Nutritionist/dietician \\
\hline 11 & $\begin{array}{l}\text { Supervised physical activity } \\
\text { session IN* }\end{array}$ & School PE teachers \\
\hline
\end{tabular}

*Fun-based physical activity session, lesson plans were designed by school physical education (PE) teachers with guidance from the project physiotherapist.

fat percentage. Secondary outcomes included self-reported attitude and behavioural variables.

\section{Anthropometry}

Body weight (to nearest $0.1 \mathrm{~kg}$ ) and body fat percentage (to nearest $0.5 \%$ ) were measured by bio-impedance body fat scale (Model: TBF-521, Tanita, Japan) with participants lightly clothed without shoes. Standing height (to the nearest $\mathrm{cm}$ ) was measured with a portable stadiometer (Model: 214, SECA). Data collection was performed by trained personnel who were blinded to group allocation and were not involved in conducting sessions for the students. BMI z-score was calculated based on age- and sex-specific reference value [38].

\section{Attitude and behavioural changes}

Students completed a set of questionnaire adopted from other studies designed for school children with a total of 20 items to investigate the attitude towards healthy eating and exercise, dietary behaviour, participation in physical activity, self-control, self-perception of weight and weight management practice $[5,21,22]$. Data were collected by trained staff reading out the questions and explaining some difficult concepts such as portion sizes of food and exercise intensity. They were also blinded to participant group allocation.

Parents completed a self-administered questionnaire on the general health condition, eating and exercise habit of their children, cooking methods used at home, frequencies of engaging in different physical activities (such as housework, outings and sports activities) with their children. The questionnaire had undergone face and content validation by pilot testing on group of parents and consultation with experts. Additional file 2 lists the contents of the questionnaires.

\section{Program evaluation}

Programme evaluation was conducted by survey completed by students, parents and teachers at the end of the project to collect their feedbacks.

\section{Sample size considerations}

Taken reference from previous study [22] and the assumption that $15 \%$ of students who had healthy eating habits $\left(\pi_{0}=\right.$ null hypothesis proportion), would increase to $30 \%$ after intervention ( $\pi=$ proportion of interest), the sample size for each group should be $52(\mathrm{~N}=104)$ giving a power of $80 \%(u=0.84)$ and level of significance at $5 \%(v=1.96)$.

$$
N=\left\{u \sqrt{ }[\pi(1-\pi)]+v \sqrt{ }\left[\pi_{0}\left(1-\pi_{0}\right)\right]\right\}^{2} /\left(\pi-\pi_{0}\right)^{2}
$$

\section{Statistical analysis}

All data were tabulated and analysed by the SPSS package version 11.5 (SPSS, Inc) and the level of significance was set at 0.05 . Chi-square test and independent $t$-test were used to assess for between-group differences in intervention and control groups during baseline. As recommended by the CONSORT guidelines for randomized trials [39], the primary analysis was performed on an intention-totreat (ITT) basis, with all participants included in the analysis according to original group allocation using linear mixed models to evaluate group differences in BMI zscore and body fat percentage at baseline and 4 months. Completer analysis was performed by the repeated measures analysis ofvariance using only intervention and control participants who attended the 4 month follow up. All models were adjusted for the baseline age and sex. McNemar test was utilized to compare the proportions of behaviour changes of and assessed for the trends of changes. BMI z-score and body fat percentage of intervention participants at baseline, 4 months and 8 months were compared pair-wisely using tests of within subject contrasts in repeated measures ANOVA to assess for program sustainability with adjustment for baseline age and sex.

\section{Results}

Among the 165 subjects, 80 and 85 were randomised to the intervention and control arms. Some students had other prior committed extra-curricular activities clashing with time schedule of this programme so 106 subjects finally enrolled in the study with 57 subjects in the intervention groups. Some students had other prior committed 
extra-curricular activities clashing with time schedule of this programme so only 106 subjects finally enrolled in the study. The numbers of students finally in intervention and control groups were not markedly different. They did not leave the study due to disappointment. It is not uncommon in Hong Kong that students enroll in many activities at different time points.

Fifty three subjects completed the 4-months intervention program and $43(75 \%)$ and $51(89 \%)$ attended the 4month and the 8-month follow up respectively. Forty-nine participants in the control arm attended the baseline assessment, 41 (84\%) were assessed at 4 month and 45 (92\%) at 8 month. There were no significant differences between participants who attended follow up $(\mathrm{n}=79)$ compared with those not attending $(\mathrm{n}=27)$ with regard to sex, age, BMI z-score or body fat percentage. No differences were found between study groups in terms of sociodemographic and anthropometric characteristics (body fat percentage and BMI z scores) at baseline except the control group were older and had a higher BMI compared to the intervention group (Table 2). Age difference has been adjusted in both intention-to-treat and completer analysis. Measure of relative BMI has been adjusted for the child's age and sex using BMI z-score, a preferred indicator for evaluating treatment success in longitudinal studies. No adverse events were reported during the intervention.

\section{Primary outcomes}

Table 3 shows the changes in BMI z-score and body fat percentage between groups and within groups at the completion of active intervention program. Intention-to-treat analyses revealed that the intervention group significantly reduced their BMI z-score $(-0.21,95 \% \mathrm{CI}-0.34$ to -0.07 , $\mathrm{P}=0.003)$ and body fat $(-2.67 \%, 95 \% \mathrm{CI}-5.12$ to -0.22 , $\mathrm{P}=0.033)$ compared to control group. For those completers, intervention group also had significant reduction in BMI z score $(-0.16,95 \% \mathrm{CI}-0.3$ to -0.02$)$ and body fat $(-3.09 \%, 95 \% \mathrm{CI}-5.91$ to -0.26$)$. Table 4 shows the change in primary outcomes in intervention group at 8 months from baseline. After 4 months maintenance period, significant reduction in BMI z-score $(-0.06,95 \% \mathrm{CI}-0.11,-0.007$, $\mathrm{P}=0.028)$ and to a lesser extent body fat $(-1.71 \%, 95 \%$ $\mathrm{CI},-3.44$ to $0.02, \mathrm{P}=0.052$ ) was observed in the intervention group. Completer analyses also showed similar results.

\section{Dietary behaviours}

At 4 months follow up, higher proportion of participants consumed healthy food, lower proportion of participants consumed unhealthy food, and eating habits were better controlled (Table 5). The improvement would be maintained or even better at 8 months follow up. Reverse trend was reported for the control group. Although no statistical significant differences were detected, the results showed opposite trend with intervention group being more positive and control group being more negative. The results of parent survey among 48 students from intervention groups also showed similar trends.

The evaluation results also showed that parents adopted healthier cooking methods with fewer parents using deepfrying in cooking from $12.5 \%$ at $\mathrm{T}_{0}$ to $7.1 \%$ at $\mathrm{T}_{1}$ and $1.8 \%$ at $\mathrm{T}_{2}$.

\section{Exercise habits}

At 4 months follow up, proportion of students fond of exercise increased from $61 \%$ to $91 \%(\mathrm{P}=0.002)$ in the intervention group (Table 5). Fear of sport injury dropped in the intervention group and reverse pattern was observed in the control group. For self reported exercise, proportion of students participating in different types of exercise increased in the intervention group but the proportion decreased in the control group except 60 minute moderate intensity exercise with (Table 5). Similarly continuous improvement trend was observed for performing strengthening exercise, aerobic exercise and moderate intensity exercise at 8 months follow up. The results were consistent with the findings from parents' survey. More parents $\left(+26.5 \% \mathrm{~T}_{1}\right.$ to $\mathrm{T}_{0} \mathrm{P}=$ 0.02 ) reported that their children were eager to do more exercise. About $50 \%$ of parent reported that their children

Table 2 Baseline characteristics of study participants according to group ${ }^{a}$

\begin{tabular}{|c|c|c|c|c|c|c|}
\hline \multirow[t]{2}{*}{ Variable } & \multicolumn{3}{|c|}{ All randomised participants (ITT) } & \multicolumn{3}{|l|}{ Completers } \\
\hline & $\begin{array}{l}\text { Intervention group } \\
(\mathrm{n}=57)\end{array}$ & $\begin{array}{l}\text { Control group } \\
(n=49)\end{array}$ & $P$ & $\begin{array}{l}\text { Intervention group } \\
(\mathrm{n}=43)\end{array}$ & $\begin{array}{l}\text { Control group } \\
(n=40)\end{array}$ & $\mathbf{P}$ \\
\hline Male, number (\%) & $38(66.7)$ & $37(75.5)$ & 0.318 & $30(70)$ & $29(70)$ & 0.982 \\
\hline Obese, number (\%) & $21(36.8)$ & $23(46.9)$ & 0.293 & $15(35)$ & $17(43)$ & 0.476 \\
\hline Age, year & $10.1(0.9)$ & 10.7(1.0) & 0.001 & $10.0(0.9)$ & $10.6(1.0)$ & 0.006 \\
\hline $\mathrm{BMl}, \mathrm{kg} / \mathrm{m}^{2}$ & $23.6(2.3)$ & $25.3(3.2)$ & 0.002 & $23.6(2.6)$ & $24.9(2.9)$ & 0.027 \\
\hline BMl z-score & $1.76(0.32)$ & $1.88(0.34)$ & 0.076 & $1.76(0.35)$ & $1.84(0.33)$ & 0.247 \\
\hline Body fat, $\%$ & $30.4(5.4)$ & $32.1(6.9)$ & 0.158 & $30.5(5.4)$ & $32.2(6.7)$ & 0.214 \\
\hline Waist to height ratio & $0.57(0.04)$ & $0.59(0.05)$ & 0.047 & $0.57(0.04)$ & $0.59(0.04)$ & 0.118 \\
\hline
\end{tabular}

${ }^{\mathrm{a}}$ Data are presented as mean (standard deviation) unless otherwise indicated.

ITT - intention-to-treat analysis, BMI- body mass index. 
Table 3 Changes in primary outcomesat 4 months from baseline ${ }^{a}$

\begin{tabular}{|c|c|c|c|c|c|c|}
\hline & \multicolumn{3}{|c|}{ All randomised participants } & \multicolumn{3}{|l|}{ Completers } \\
\hline & $\begin{array}{l}\text { Intervention group } \\
(n=57)\end{array}$ & $\begin{array}{l}\text { Control group } \\
(n=49)\end{array}$ & $\begin{array}{l}\text { Group difference }{ }^{1} \\
\text { (intervention } \\
\text { minus control) }\end{array}$ & $\begin{array}{l}\text { Intervention } \\
\text { group }(n=43)\end{array}$ & $\begin{array}{l}\text { Control group } \\
(n=40)\end{array}$ & $\begin{array}{l}\text { Group difference }^{2} \\
\text { (intervention } \\
\text { minus control) }\end{array}$ \\
\hline $\begin{array}{l}\text { BMI } \\
\text { Z-score }\end{array}$ & $0.02(-0.17$ to 0.21$)$ & $0.48^{* *}(0.25$ to 0.71$)$ & $-0.21^{*}(-0.34$ to -0.07$)$ & $-0.04^{* *}(-0.01$ to -0.08$)$ & $0.02(-0.03$ to 0.06$)$ & $-0.16^{*}(-0.30$ to -0.02$)$ \\
\hline $\begin{array}{l}\text { Body } \\
\text { fat (\%) }\end{array}$ & $0.40(-0.56$ to 1.37$)$ & $1.92^{* *}(0.72$ to 3.13$)$ & $-2.67^{*}(-5.12$ to -0.22$)$ & $0.54(-0.76$ to 1.83$)$ & $2.36^{* *}$ (0.92 to 3.80$)$ & $-3.09^{*}(-5.91$ to -0.26$)$ \\
\hline
\end{tabular}

${ }^{\mathrm{a} D a t a}$ are presented as mean (95\% confidence interval).

${ }^{1}$ Linear mixed model, adjusted for baseline age and sex.

${ }^{2}$ Repeated measure of ANOVA, adjusted for baseline age and sex.

${ }^{*} \mathrm{P}<0.05$.

**P $<0.005$.

increased participation in sports activities from $T_{0}$ to $T_{2}$. A significant higher proportion of parents encouraged their children to engage in sports $\left(+34 \%\right.$ from $\mathrm{T}_{0}$ to $\mathrm{T}_{1}, \mathrm{P}<$ 0.001 ), and discussed the benefit of exercises and negative effects of physical inactivity with their children $\left(+27.7 \% \mathrm{~T}_{0}\right.$ to $\left.\mathrm{T}_{1}, \mathrm{p}=0.004\right)$. A significant higher proportion of parents praised their children for doing exercise $\left(+27.7 \%\right.$ from $\mathrm{T}_{0}$ to $\mathrm{T}_{1}, \mathrm{p}=0.004$ ) and bought sports equipment for their children $\left(=25.6 \%\right.$ from $\mathrm{T}_{0}$ to $\left.\mathrm{T}_{1}, \mathrm{p}=0.002\right)$. More parents also reported doing 20 minutes exercise with their children at least once per week $\left(+18.2 \%\right.$ from $\mathrm{T}_{0}$ to $\mathrm{T}_{1) \text {. }}$

\section{Impact of project on empowering schools to foster a supportive healthy living environment}

Participating schools run various school-based healthpromoting programmes ranging from 5 to 34 activities for students and their parents under project team support and guidance during the project period. Out of a total of 10 scores, participating schools rated an average of 8.07 for sufficiency of support from project team. Mean score was 8.67 for agreeing the programme enhanced the teachers' competency in running school-based weight management programme and understanding of the fitness status of students, and broaden the school's horizon in health policy and education.

\section{Programme feedback from students and parents}

A total of 67 feedback forms were returned from students of both intervention and control groups. Majority of students expressed that the programme had enhanced their knowledge on healthy eating and exercise for weight control, and also raised their interest in healthy eating and sport activities. Nearly $70 \%$ of students expressed their wishes to have similar programme in future. For overall rating of the programme, the mean score was 7.27 out of total of 10 with $\mathrm{SD} \pm 2.44$.

A total of 77 feedback forms were returned from parents. Over 90\% reported that the programme had enhanced their knowledge in helping their children eating healthily and exercising for weight control as well as arousing their awareness on importance of weight control, and increased their understanding on the fitness status of their children. Over $70 \%$ of the parents felt that the programme had posed positive influence to their children's self-esteem and also parent-child relationship. The mean score rated by parents was 7.89 out of a total of 10 with $S D \pm 1.48$.

\section{Discussion}

This pilot trial study addressed the need of focusing on a weight management programme for overweight and obese children delivered in school setting. To the best of our knowledge, it is one of the first weight management trial evaluated in a school setting versus a clinical or community setting. We demonstrated that a 4-month school-based child weight management programmes delivered in HPS is efficacious for obesity management after intervention and at 8-month follow up. Significant changes in BMI z-score and percent body fat were observed. The reduction in BMI z-score are of similar magnitude as reported in 2009 Cochrane review of lifestyle trials in children under 12 years old [37]. Although statistical significant improvements were observed only on few health behaviours with established linked to weight control, reverse trend was observed for control group. The findings still alert the possible impact on behavioural change.

Table 4 Changes in anthropometric outcome variables of intervention group at 8 months from baseline ${ }^{1}(n=41)$

\begin{tabular}{|c|c|c|c|c|}
\hline & \multicolumn{2}{|l|}{ Change 4-8 months } & \multicolumn{2}{|l|}{ Change $0-8$ months } \\
\hline & Mean $(95 \% \mathrm{Cl})$ & $P$ & Mean $(95 \% \mathrm{Cl})$ & $\mathbf{P}$ \\
\hline BMI z-score & $-0.06(-0.11$ to -0.01$)$ & 0.028 & $-0.11(-0.17$ to -0.005$)$ & 0.001 \\
\hline Body fat (\%) & $-1.71(-3.44$ to 0.02$)$ & 0.052 & $-1.26(-2.6$ to 0.85$)$ & 0.066 \\
\hline
\end{tabular}

${ }^{1}$ Repeated measure of ANOVA, adjusted for baseline age and sex. 
Table 5 Self-reported dietary and exercise behaviourat Baseline and 4 months in intervention and control group students

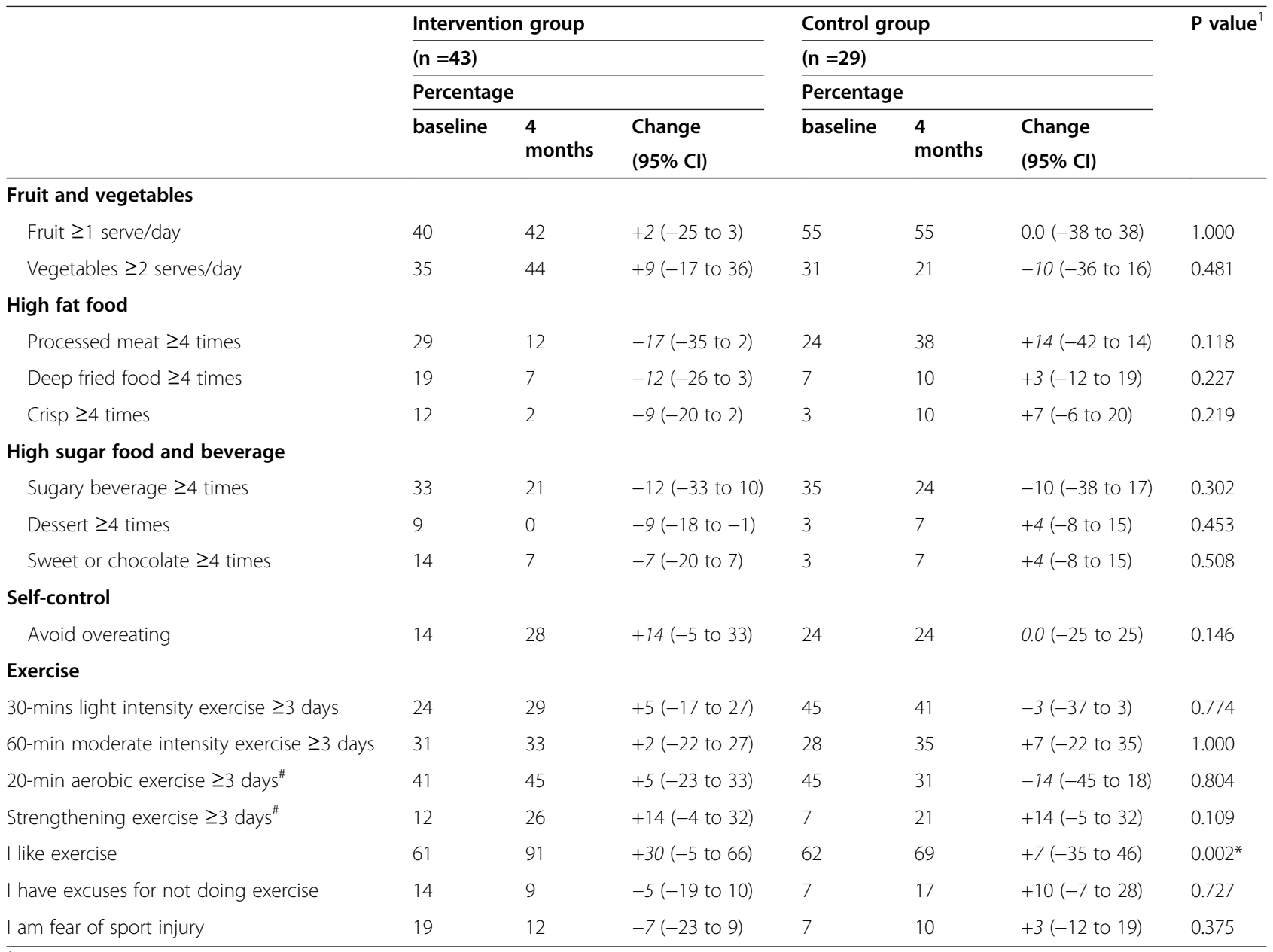

${ }^{1} \mathrm{P}$-values are for the change between 3 and 6 months by the McNemar's Test.

Italic highlights the effect size in opposite direction or statistical significance at level of P $0.05 \%$.

Integration of knowledge concerning healthy dietary intake, physical activity habits, and smoking and drug prevention through specified modified school curriculum needs to act in parallel with other strategies to tackle the environmental and economic limitations [28]. An Active Programme Promoting Lifestyle Education in School in England [40,41] and some previous studies mainly showed change in nutritional knowledge rather than significant changes in behaviour or short to intermediate term health outcomes $[42,43]$. Cost-effective intervention should target children at higher risk and devote more resources to intensive interventions integrating nutrition and physical activities with strong family components similar to this study and some other recent studies. [23,43].

The WHO concept of HPS is seen as most promising approach as it incorporates actions addressing the school physical and social environment not just health education. The interventions adopted in this study were embedded in a supportive environment for HPS. If the targets were weight loss and weight maintenance, the insignificant findings of wait-list schools despite the supportive environment suggest that the HPS model ought to be supplemented by intensive interventions and parental engagement. The researchers of this study have successful implemented HPS in Hong Kong demonstrating health improvement amongst students $[23,29]$. This programme building on the successful model of HPS has demonstrated the potential of overcoming the environmental and economic barriers, and moving beyond curriculum as curriculum approach alone had limited effectiveness in improvement of physical activities. The school environment would shape youth health via common pathways [44]. This might explain why not many other school based weight control programmes showed improvement of anthropometric measures within a short period of time. Building on existing HPS framework would add synergy to school based health promotion initiatives. 
There are limitations of this pilot study. We are unable to determine if the environment component was essential to success because of design limitations in this pilot study. Further research should compare students receiving group education/counselling and parent education alone with students receiving the intervention within boarder HPS activities. The sample size of this study might not have adequate power to detect the difference of behaviours between intervention and control groups with statistical significant. Behaviour outcomes should also be quantified more precisely. It was not done in this pilot study to avoid over burdening the participants. Statistical significant difference of mean age 10.1 vs 10.7 was found between intervention and control groups but the impact on health behaviours would be minimal. Although the programme has received very positive feedbacks from students, parents and schools, the duration of intervention was too short for monitoring longer term effects. The heavy commitment of students in other activities also limited the participation of eligible students in this programme. Education sector should take note of the findings and evaluation from stakeholders of this pilot programme and accord higher priority for school based weight management programme.

Our programme puts a strong emphasis on parental participation with more parents engaging in exercise, improved cooking styles and discussing the importance of physical activities with their children, and continued to do so after intervention period. A systematic review of environmental correlates of obesity-related youth dietary behaviours shows consistent associations between parental intake and children's fat and their fruit/vegetable intakes [45]. Long term school-parent partnership and education intervention has shown positive statistical significant results in overall physical activity incidence, and adiposity and fitness measures such as BMI, sit and reach flexibility, and $20 \mathrm{~m}$ shuttle run [46]. It would also help families at lower socio-economic status to ameliorate the moderation effect of socio-economic status on relationship between psychosocial predictors and healthy eating of students [47].

\section{Conclusion}

The scale of the obesity epidemic makes it difficult to manage overweight and obese children on one to one basis through clinical services alone. This study has demonstrated the efficacy of school-based weight management programme targeting overweight and obese children with intensive education and counselling, and parental engagement operating within a broader HPS approach. The programme needs to incorporate socio-environmental factors, personal factors and behavioural factors putting the issue in the context of everyday life [48], and strategies based exclusively on diet may not stop weight gain [23].

\section{Additional files}

Additional file 1: Intervention at school level and strategies to involve the parents.

Additional file 2: Students' dietary behaviour in the week prior to the survey at T0, T1 and T2.

\section{Competing interests}

The authors declare that they have no competing interests.

\section{Authors' contributions}

Conceived and design of the study: AL, MH, VMWK, ACMK. Field work: MH, VMWK, ACMK. Data Analysis: AL, MH, VMWK. Preparation of manuscript: AL, $\mathrm{MH}$. Overall supervision: AL. All authors read and approved the final manuscript.

\section{Acknowledgements}

We would like to thank all participating schools for their efforts. We would also like to thank all the participating children and their parents.

\section{Funding}

This study was supported by the Healthcare and Promotion Fund (HCPF 20060524), Hong Kong Special Administrative Region Government (HKSAR). This project contributed to the award of 'Most Outstanding Capacity Building in Health Promotion' by Food and Health Bureau, HKSAR.

\section{Author details}

${ }^{1}$ Centre for Health Education and Health Promotion, JC School of Public Health and Primary Care, The Chinese University of Hong Kong, 4th Floor, Lek Yuen Health Centre, Shatin, New Territory, Hong Kong. ${ }^{2}$ The Children Hospital at Westmead Clinical School, University of Sydney, Sydney, Australia.

Received: 6 September 2013 Accepted: 15 October 2014

Published: 3 November 2014

\section{References}

1. Wang $Y$, Lobstein $T$ : Worldwide trends in childhood overweight and obesity. Int J Pediatr Obes 2006, 1(1):1-25.

2. World Health Organization: Childhood Overweight and Obesity; 2011. www. who.int/dietphysicalactivity/childhood/en/ Accessed on 7 October 2014.

3. Yu Z, Han S, Chu J, Xu Z, Zhu C, Guo X: Trends in overweight and obesity among children and adolescents in China from 1981 to 2010: a metaanalysis. PLoS One 2012, 7(12):e51949. doi:10.1371/journal.pone.0051949.

4. Lee A: Trends in Hong Kong and Macao and other Chinese Communities. In Childhood Obesity Prevention: International Research, Controversies, and Intervention. Edited by O'Dea JA, Erickesn M. New York, USA: Oxford University Press; 2010.

5. Lee $A$, Ho M, Keung V: Global epidemics of childhood obesity is hitting a quiet corner in Asia: case study in Macao. Int J of Ped Obes 2010, 6(2-2):e252-e256.

6. Lobstein T, Baur L, Jackson-Leach R: The childhood obesity epidemics. In Preventing Childhood Obesity. Edited by Waters E, Swinburn B, Seidell J, Uauy R. Oxford, UK: Wiley Blackwell; 2010.

7. Schmidt MI, Duncan BB, Azevedo c Silva G, Menezes AM, Monterio CA, Sandhi Maria Barreto SM, Chor D, Meneze PR: Chronic non-communicable diseases in Brazil burden and current challenges. Lancet 2011, 377:1676-1679.

8. Lobstein T, Baur L, Uauy R: The IASO International Obesity Taskforce: obesity in children and young people: a crisis in public health. Obes Rev 2004, 5(Suppl: 1):4-85.

9. Reilly JJ, Methven E, McDowell ZC, Hacking B, Alexander D, Stewart L, Kelnar CJH: Health consequences of obesity. Arch Dis Child 2003, 88:748-752. 2.

10. Lopez AD, Mathers CD, Ezzati M, Jamison DT, Murray CJ: Global and regional burden of disease and risk factors, 2001: systematic analysis of population heath data. Lancet 2006, 367:1747-1757.

11. DóraSigfúsdóttir I, LogiKristjásson Á, Allegrate JP: Health behaviour and academic achievement in Icelandic school children. Health Educ Res 2007, 22(1):70-80.

12. Ho M, Garnett SP, Baur L, Burrows T, Stewart L, Neve M, Collins C: Effectiveness of lifestyle interventions in child obesity: systematic review with meta-analysis. Pediatrics 2012, 130:e1647-e1671. 
13. Jiang JX, Xia XL, Griener T, Lian GL, Rosenqvist U: A two year family based behaviour treatment for obese children. Arch Dis Child 2005, 90(12):1235-1238.

14. Huang SH, Weng KP, Hsieh KS, Ou SF, Lin PY, Chien KJ, Ho TY: Effects of a classroom-based weight-control intervention on cardiovascular disease in elementary-school obese children. Acta Paediatr Taiwan 2007, 48(4):201-206.

15. Waters E, Haby M, Wake M, Salmon L: Public health and preventive health care in children: current practices of Victorian GPs and barriers to participation. Med J Aus 2000, 173:68-71.

16. VanSluijs EMF, Van Poppel MNM, TwJsk JWR, Chin A, Paw MJ, Calfas KJ, Van Mechelen W: Effect of a tailored physical activity intervention delivered in general practice settings: results of a randomized controlled trial. Am J Public Health 2005, 95:1825-1831.

17. McCallum Z, Wake M, Gerner B, Baur LA, Gibbons K, Harris C, Naughton G, Riess C, Sanci L, Sheehan J, Ukoumunne OC, Waters E: Outcome data from the LEAP (Live, Eat and Play trail: a randomised controlled trial of primary care intervention for childhood overweight/mild obesity. Int $J$ Obes 2007, 31:630-636

18. Stice $E$, Shaw $H$, Marti $C N$ : A meta-analytic review of obesity prevention programs for children and adolescents; the skinny on interventions that work. Psychol Bull 2006, 132:667-691.

19. Ward DS, Ries AV, Tabak R: Environment and policy interventions to prevent obesity in children. In Childhood Obesity Prevention: International Research, Controversies, and Intervention. Edited by O'Dea J, Eriksen M. New York, USA: Oxford University Press; 2010.

20. Swinburn B, Sacks G, Hall KD, McPherson K, Finegood DT, Moodie ML, Gortmaker SL: The global obesity pandemic: shaped by global drivers and local environments. Lancet 2011, 378:804-815.

21. Arredonodo EM, Elder JP, Ayala GX, Campbell N, Baquero B, Duerksen S: Is parenting style related to children's healthy eating and physical activity in Latin families? Health Educ Res 2006, 21:862-871.

22. Yung $T$, Lee $A, H o M$, Keung $V$, Lee J: Maternal influences on fruit and vegetable consumption of school children: case study in Hong Kong. Maternal Child Nutr 2010, 6(2):190-195.

23. Katz DL, Connell MO, Njike WY, Yeh MC, Nawaz H: Strategies for the prevention and control of obesity in the school setting: systematic review and meta-analysis. Int J Obes 2008, 32:1780-1789.

24. Mâsse L, De NE: School nutritional capacity, resources and practices are associated with availability of food beverage items in schools. Int J Behav Nutr Phys Act 2013, 10:26. http://www.ijbnpa.org/content/10/1/26.

25. Brug J, Te Velde S, De Bourdeaudhuij I, Kremers S: Evidence of the influence of home and family environment. In Preventing Childhood Obesity. Edited by Waters E, Swinburn B, Seidell J, Uauy R. Oxford, UK: Wiley Blackwell; 2010

26. Brown T, Summerbell C: Systematic review of school-based interventions that focus on changing dietary intake and physical activity levels to prevent childhood obesity: an update to the obesity guidance produced by the National Institute for Health and Clinical Excellence. Obes Rev 2009, 10(1):110-141.

27. Li M, Li S, Baur L, Huxley RR: A systematic review of school-based intervention studies for the prevention or reduction of excess weight among Chinese children and adolescents. Obes Rev 2008, 9(6):548-559.

28. Shaya FT, Flores D, Gbarayor CM, Wang J: School-based obesity interventions: a literature review. J Sch Health 2008, 78(4):189-196.

29. Lee $A$, Ho M, Keung V: Healthy setting as an ecological model for prevention of childhood obesity. Res Sports Med 2010, 18(1):49-61.

30. Sekhobo JP, Egglefield K, Edmunds LS, Shackman G: Evidence of the adoption and implementation of a statewide childhood obesity prevention initiative in the New York State WIC Program: the NY Fit WIC process evaluation. Health Educ Res 2010, 27(2):281-291.

31. Neumark-Sztainer D, Haines J, Robinson-O'Brien R, Hannan PJ, Robins M, Morris B, Petrick CA: 'Ready. Set ACTION!' A theatre-based obesity prevention for children: a feasibility study. Health Edu Res 2009, 24(3):407-420.

32. Cunha DB, de Souza BSN, Pereira RA, Sichieri R: Effectiveness of a randomised school-based intervention involving families and teachers to prevent excessive weight gain among adolescents in Brazil. PLoS One 2013, 8(2):e57498.
33. Dooris M: Holistic and sustainable health improvement: the contribution of the settings-based approach to health promotion. Perspectives Public Health 2009, 129(1):29-36.

34. Moon AM, Mullee MA, Rogers $L$, Thompson RL, Speller V, Roderick P: Helping schools to become health-promoting environments - an evaluation of the Wessex Healthy Schools Award. Health Promot Int 2009, 14:111-122.

35. Lee A, Cheng F, Fung Y, St Leger L: Can health promoting schools contribute to the better health and well being of young people: Hong Kong experience? J Epidemiol Community Health 2006, 60:530-536.

36. Singh AS, Chinapaw MJM, Brug J, Van Mechelen W: Process evaluation of a school-based weigth gain prevention program: the Dutch Obesity Intervention in Teenagers (DOiT). Health Edu Res 2009, 24(5):772-777.

37. Oude Luttikhuis $H$, Baur L, Jansen H, Shrewsbury VA, O'Malley C, Stolk RP, Summerbell CD: Interventions for treating obesity in children. Cochrane Database Syst Rev 2009, 3: doi:10.1002/14651858.CD001872.pub2.

38. Kuczmarski RJ, Ogden CL, Grummer-Strawn LM, Flegal KM, Mei S, Guo S, Wei R, Mei Z, Curtin LR, Roche AF, Johnson CL: CDC growth charts: United States. Adv Data 2000, 314:1-27.

39. Moher D, Schulz KF, Altman DG: The CONSORT statement: revised recommendations for improving the quality of reports of parallel-group randomised trials. Lancet 2001, 357(9263):1191-1194.

40. Sahota P, Rudolf MCJ, Dixey R, Hill AJ, Barth JH, Cade J: Evaluation of implementation and effect of primary school based intervention to reduce risk factors for obesity. BMJ 2001, 323:10279.

41. Sahota P, Rudolf MCJ, Dixey R, Hill AJ, Barth JH, Cade J: Randomised controlled trial of primary school based intervention to reduce risk factors for obesity. BMJ 2001, 323:1029-1032.

42. Atkinson RL, Nitzkle SA: School based programmes on obesity: increase knowledge about nutrition but do not change eating habits by much. BMJ 2001, 323:1018. doi:10.1136/bmj.323.7320.1018.

43. Uteer J, Scragg R, Robinson E, Warbrick J, Faeamani G, Foroughian S, Dewes O, Moodile M, Swinburn BA: Evaluation of the living 4 life project: a youth-led, school-based obesity prevention study. Obes Rev 2011, 12(suppl 2):51-60.

44. Jamal F, Fletcher A, Harden A, Wells H, Thomas J, Bonell C: The school environment and student health: a systematic review and meta-ethnography of qualitative research. BMC Public Health 2013, 13:795.

45. Van der Horst K, Oenema A, Ferreira I, Wendel-Vos W, Giskes K, van Lenthe F, Brug J: A systematic review of environmental correlates of obesity-related dietary behaviours in youth. Health Educ Res 2007, 22(2):203-226.

46. Kafatos A, Manios Y, Moschandreas J: Health and nutrition education in primary schools of Crete: follow-up changes in body mass index and overweight status. Eur J Clin Nutr 2005, 59(9):1090-1092.

47. Sandvick C, Gjestad R, Samdal O, Burg J, Kleep Kl: Does Socio-economic status moderate the associations between psycho-socal predictors and fruit intake om school children? The Pro-Children Study. Health Educ Res 2010, 25(1):121-134.

48. Neumark-Sztainer D, Flattum C, Hannan PJ, Staey MT, Baeuer K, Feldmen SB, Petrich CA: New moves- preventing weight related problems in adolescent girls: a group randomized study. Am J Prev Med 2010, 39(5):421-432.

doi:10.1186/1471-2458-14-1128

Cite this article as: Lee et al:: Childhood obesity management shifting from health care system to school system: intervention study of schoolbased weight management programme. BMC Public Health 2014 14:1128.

\section{Submit your next manuscript to BioMed Central and take full advantage of:}

- Convenient online submission

- Thorough peer review

- No space constraints or color figure charges

- Immediate publication on acceptance

- Inclusion in PubMed, CAS, Scopus and Google Scholar

- Research which is freely available for redistribution 